\title{
The Tumor Microenvironment of Cutaneous Squamous Cell Carcinoma in Immunosuppressed Patients
}

\section{Mica Glaun}

The University of Texas MD Anderson Cancer Center https://orcid.org/0000-0003-4814-3724

\section{Frederico Gleber-Netto}

The University of Texas MD Anderson Cancer Center https://orcid.org/0000-0001-7847-9902

\section{Priyadharsini Nagarajan}

The University of Texas MD Anderson Cancer Center

\section{Tongxin Xie}

University of Texas MD Anderson Cancer Center

\section{Jennifer Covello}

University of Texas MD Anderson Cancer Center

\section{Shamima Akhter}

University of Texas MD Anderson Cancer Center

\section{Adebayo Adewale}

University of Texas MD Anderson Cancer Center

\section{Erez Baruch}

McGovern Medical School at The University of Texas Health Science Center

\section{Michael Wong}

The University of Texas MD Anderson Cancer Center

\section{Emily Chu}

Hospital of the University of Pennsylvania

\section{Kenneth Tsai}

Moffitt Cancer Center https://orcid.org/0000-0001-5325-212X

\section{Elsa Flores}

Moffitt Cancer Center https://orcid.org/0000-0002-6173-2403

\section{Michael Migden}

The University of Texas MD Anderson Cancer Center

\section{Deborah Silverman}

University of Texas MD Anderson Cancer Center

\section{Ryan Goepfert}

The University of Texas MD Anderson Cancer Center

\section{Yejing Ge}


University of Texas MD Anderson Cancer Center https://orcid.org/0000-0002-2555-7900

\section{Padmanee Sharma}

MD Anderson Cancer Center https://orcid.org/0000-0003-4658-055X

James Allison

Jeffrey Myers

The University of Texas MD Anderson Cancer Center

\section{Neil Gross}

The University of Texas MD Anderson Cancer Center

Moran Amit ( $\triangle$ mamit@mdanderson.org )

M.D. ANDERSON CANCER CEN https://orcid.org/0000-0002-9720-7766

\section{Article}

Keywords: Nonmelanoma skin cancer, cutaneous squamous cell carcinoma (cSCC), immunosuppression Posted Date: November 16th, 2021

DOI: https://doi.org/10.21203/rs.3.rs-1048284/v1

License: (c) (i) This work is licensed under a Creative Commons Attribution 4.0 International License. Read Full License 


\section{The Tumor Microenvironment of Cutaneous Squamous Cell Carcinoma in Immunosuppressed Patients}

${ }^{\#}$ Mica D. E. Glaun ${ }^{1},{ }^{\#}$ Frederico O. Gleber-Netto ${ }^{1}$, Priyadharsini Nagarajan ${ }^{2}$, Tongxin Xie ${ }^{1}$, Jennifer Covello $^{1}$, Shamima Akhter ${ }^{1}$, Adebayo Adewale ${ }^{1}$, Erez N. Baruch ${ }^{3}$, Michael K. Wong ${ }^{4}$, Emily Y. Chu, Kenneth Y. Tsai ${ }^{5}$, Elsa R. Flores ${ }^{6}$, Michael R. Migden ${ }^{7}$, Deborah A. Silverman ${ }^{4}$, Ryan P. Goepfert ${ }^{1}$, Yejing Ge ${ }^{4}$, Padmanee Sharma ${ }^{8}$, James P. Allison ${ }^{9}$, Jeffrey N. Myers ${ }^{1}, *$ Neil D. Gross ${ }^{1}$, and *Moran Amit $^{1}$

$\#=$ contributed equally

${ }^{1}$ Department of Head and Neck Surgery, The University of Texas MD Anderson Cancer Center, Houston, Texas, USA.

${ }^{2}$ Department of Pathology, The University of Texas MD Anderson Cancer Center, Houston, Texas, USA.

${ }^{3}$ Department of Internal Medicine, McGovern Medical School at The University of Texas Health Science Center, Houston, TX, USA

${ }^{4}$ Department of Melanoma Medical Oncology, The University of Texas MD Anderson Cancer Center, Houston, Texas, USA.

${ }^{5}$ Department of Pathology, Moffitt Cancer Center, Tampa, Florida, USA.

${ }^{6}$ Department of Molecular Oncology, Moffitt Cancer Center, Tampa, Florida, USA.

${ }^{7}$ Department of Dermatology, The University of Texas MD Anderson Cancer Center, Houston, Texas.

${ }^{8}$ Department of Genitourinary Medical Oncology, The University of Texas MD Anderson Cancer Center, Houston, Texas

${ }^{9}$ Department of Immunology, The University of Texas MD Anderson Cancer Center, Houston, Texas Department of Dermatology, University of Pennsylvania 
* = Corresponding Authors: Moran Amit, MD, PhD, Department of Head and Neck Surgery, Unit 123, The University of Texas MD Anderson Cancer Center, 1515 Holcombe Blvd., Houston, TX 77030, USA (mamit@mdanderson.org). Office number: 713-794-5304; Neil D. Gross, MD, Department of Head and Neck Surgery, Unit 1445, The University of Texas MD Anderson Cancer Center, 1515 Holcombe Blvd., Houston, TX 77030, USA (ngross@mdanderson.org). Office number: 713-794-1112 


\begin{abstract}
:
Nonmelanoma skin cancer is the most common malignancy and immunosuppression is a key risk factor. Despite the promising data demonstrating the efficacy of immune checkpoint inhibition in the treatment of cutaneous squamous cell carcinoma (cSCC), most immunosuppressed patients are not included in immunotherapy trials due to the risk for toxicity and the lack of data regarding $\mathrm{cSCC}$ immune landscape in immunosuppressed patients. To characterize the specific alterations accounting for a diminished antitumor immune response in immunosuppressed patients, we used multispectral imaging on cSCC pathology specimens from immunosuppressed patients with age and stage matched immunocompetent controls. We show that densities of $\mathrm{CD}^{+} 8^{+}$cells are diminished in immunosuppressed patients. Moreover, using an organ transplant recipient cohort from two cancer centers, we found significantly lower effector T-cells densities as compared with controls. Overall, density of $\mathrm{CD} 68^{+}$and $\mathrm{CD} 8^{+} \mathrm{LAG}^{+}$cells were predictors of disease-specific and disease-free survival. These findings provide insight into the patterns of immune infiltrating cells in patients with different types of immunosuppression; leading us to conjecture that different immune based therapeutic approaches may be needed to treat immunosuppressed cSCC patients.
\end{abstract}




\section{Introduction}

The most common malignancy in the United States is non-melanoma skin cancer, which is increasing in incidence. Cutaneous squamous cell carcinoma (cSCC) is the second most common, form of nonmelanoma skin cancer. Risk factors for non-melanoma skin cancer include a history of chronic ultraviolet radiation exposure, advanced age, decreased skin pigment, and a history of immunosuppression. ${ }^{1,2}$ Although surgery is often curative, it has associated medical costs as well as aesthetic and functional sequelae, and cSCC patients remain at high risk for secondary skin malignancies. Furthermore, patients whose cancers are too advanced for curative surgery are often given immunotherapy. Recent clinical trials have demonstrated that immunotherapy has durable efficacy in advanced cSCC. ${ }^{3,4,5}$ However, systemically administered immune checkpoint inhibitor infusions pose an increased risk for patients who are chronically immunosuppressed, and therefore these patients have been excluded from most clinical trials investigating the efficacy of this highly effective therapy. ${ }^{6,7}$ Knowledge of the alterations in the tumor immune microenvironment (TME), and especially the tumor T-cell microenvironment, in immunosuppressed (IS) cSCC patients remains lacking. We and others have shown that local delivery of immunostimulatory treatments can be used safely and with great effect in the treatment of immunosuppressed cancer patients. ${ }^{8}$ In order, to broaden the application of locally delivered immune modulatory treatments to immunosuppressed patients $\mathrm{cSCC}$, we used multispectral imaging on their cSCC pathology specimens to characterize the tumor immune micro-environment (TME) and compared them to $\mathrm{cSCC}$ from immunocompetent controls.

Chronic immunosuppression, whether iatrogenic or pathologic, impairs both the innate and adaptive arms of the immune system, ultimately compromising immunosurveillance, the process by which T cells monitor, identify, and destroy cancer cells. IS patients have defective systemic immune responses, but whether their TME is similarly immune-deficient remains unknown. Immune checkpoint inhibitors target immune checkpoints on the surface of $\mathrm{T}$ cells or their cognate ligands on tumor cells, thereby preventing the inactivation of $\mathrm{T}$ cells and potentiating an anti-tumor immune response. The 
degree to which $\mathrm{cSCC}$ tumors in IS patients have either the number or phenotype of $\mathrm{T}$ cells or other supportive anti-tumor immune cells required to generate an immune response is yet to be fully elucidated.

The purpose of the present study was to delineate how the TME in IS cSCC patients differs from that in immunocompetent (IC) cSCC patients. We also sought to gain insight into the evolution of the immune landscape throughout tumorigenesis in cSCC IS patients with different immunosuppression etiologies.

\section{Results}

\section{Clinical characteristics}

We included $103 \mathrm{cSCC}$ patients comprised of 61 IS patients and 42 age- and stage-matched IC patients treated at MD Anderson Cancer Center; between 1998 to 2020 with a median follow up of 88 months, range 6-240 months (Table 1). The most common T class was T3 $(\mathrm{n}=41[40 \%])$ followed by T1 $(\mathrm{n}=37$ [36\%]). All 61 IS patients (100\%) and 41 IC patients (97\%) underwent surgery. Adjuvant radiation was administered more often in the IS population $(n=19[31 \%])$ than in the IC population $(n=4[9 \%])$. In the IS cohort, 34 patients (55\%) had locoregional recurrence, and 6 patients (10\%) developed distant metastasis. In the IC cohort, 19 patients (45\%) had locoregional recurrence, and 3 patients (7\%) developed distant metastasis. In the IC cohort, 19 patients (45\%) had locoregional recurrence, and 3 patients (7\%) developed distant metastasis.

An additional cohort of organ transplantation patients was included to enable characterization of this unique population. This cohort was comprised of 12 patients, $6(50 \%)$ with kidney transplantation, 5 (41\%) with liver transplantation, and $1(8 \%)$ with double lung transplantation. Further clinical demographics of this cohort and the patients' immunosuppressive therapies is available in Supplemental Table 1. 


\section{Antigen presenting cells are depleted in immunosuppressed patients with cSCC}

Interaction between injured keratinocytes and macrophages has been associated with leukocyte recruitment, chronic inflammation, immunoediting initiation, and eventual malignant transformation. ${ }^{9,10}$ To analyze the nature of innate immunity between IS and IC cSCC patients, we compared the density of $\mathrm{CD}^{+} 8^{+}$antigen-presenting cells (APCs; i.e., macrophages and dendritic cells) in the TME within tumor and within stromal area (Figure 1 A-B). While both compartments are important for an efficient antitumor immune response, an effective transition between the intraepithelial (tumor) and stromal compartments is critical and highly regulated. ${ }^{11}$ First, we assessed APCs' distribution within the TME by evaluating the densities of $\mathrm{CD} 68^{+}$cells in the tumor and surrounding stroma specimens separately. In the IS cohort, the $\mathrm{CD}^{+} 8^{+}$APC density in the cytokeratin (CK)-negative stroma $\left(154 \pm 33.4\right.$ cells $\left./ \mathrm{mm}^{2}\right)$ was significantly higher than that in the $\mathrm{CK}^{+}$tumor $\left(38 \pm 19.9\right.$ cells $\left./ \mathrm{mm}^{2} ; P<0.0001\right)$. Compared with the IC cohort, the IS cohort had significantly lower densities of tumoral CD68 ${ }^{+}$APCs $\left(56 \pm 16.7\right.$ cells $/ \mathrm{mm}^{2}$ vs. $38 \pm 19.9$ cells $\left./ \mathrm{mm}^{2} ; P=0.033\right)$ and stromal $\mathrm{CD} 68^{+}$APCs $\left(306 \pm 67.9\right.$ cells $/ \mathrm{mm}^{2}$ vs. $154 \pm 33.4$ cells $/ \mathrm{mm}^{2} ; P=$ 0.0044) (Figure 1B).

Given the significant differences in $\mathrm{CD}^{+} 8^{+}$APC densities, we investigated the differences in $\mathrm{CD}^{+} 8^{+}$programmed death ligand 1 (PDL1)-positive cell populations between $\mathrm{CD} 68^{+} \mathrm{APC}$ in IS and IC patients. In patients with solid tumors such and breast or lung cancer, elevated PDL1 expression in macrophages is associated with longer overall survival ${ }^{12-16}$. The tumoral and stromal $\mathrm{CD} 68^{+} \mathrm{PDL} 1^{+}$cell densities of the IS cohort and IC cohort did not differ significantly. However, in the IS cohort, the tumoral $\mathrm{CD} 8^{+} \mathrm{PDL1}^{+}$cell density $\left(186.4 \pm 48.9\right.$ cells $\left./ \mathrm{mm}^{2}\right)$ was significantly higher than the stromal $\mathrm{CD} 8^{+} \mathrm{PDL}^{+}$cell density $\left(90.3 \pm 15.03\right.$ cells $\left./ \mathrm{mm}^{2}\right)(P<0.0001)$. In the IC cohort, the tumoral $\mathrm{CD} 8^{+} \mathrm{PDL1}^{+}$cell density $\left(32.5 \pm 8.76\right.$ cells $\left./ \mathrm{mm}^{2}\right)$ and stromal $\mathrm{CD} 68^{+} \mathrm{PDL1}^{+}$cell density $(96 \pm 16.6$ cells $\left./ \mathrm{mm}^{2}\right)$ did not differ significantly $(P=0.2)$. 


\section{T cell abundance is similar in immunocompetent and immunosuppressed patients with cSCC}

Next, we studied $\mathrm{CD} 4^{+}$helper T cells and found no difference in the overall density of $\mathrm{CD} 4^{+}$cells between the IC and IS cohorts (Figure 1A-B). We also found no difference between the tumoral or stromal densities of $\mathrm{CD}^{+} \mathrm{FOXP}^{+}$regulatory $\mathrm{T}$ cells (Tregs) between the IC and IS cohorts (Figure 1C).

Spatial analysis revealed that the density of stromal $\mathrm{CD} 8^{+}$cells was significantly higher than that of tumoral CD8 ${ }^{+}$cells in both the IC cohort $\left(452 \pm 99.9\right.$ cells $/ \mathrm{mm}^{2}$ vs. $88 \pm 21.5$ cells $\left./ \mathrm{mm}^{2} ; P<0.0001\right)$ and IS cohort $\left(352 \pm 94.9\right.$ cells $/ \mathrm{mm}^{2}$ vs. $75 \pm 24.9$ cells $\left./ \mathrm{mm}^{2} ; P<0.0001\right)$. Compared with the IC cohort, the IS cohort had lower abundances of both tumoral $\mathrm{CD}^{+}$cells $\left(88.6 \pm 21.5\right.$ cells $/ \mathrm{mm}^{2}$ vs. $75.5 \pm 24.9$ cells $\left./ \mathrm{mm}^{2} ; P=0.152\right)$ and stromal $\mathrm{CD} 8^{+}$cells $\left(452 \pm 99.9\right.$ cells $/ \mathrm{mm}^{2}$ vs. $352 \pm 94.9$ cells $/ \mathrm{mm}^{2} ; P=$ 0.0812), but these differences were not significant.

Lymphocyte activation gene 3 (LAG3) is an immune checkpoint and potential marker of T-cell activation and exhaustion. ${ }^{17-19}$ We found no significant differences in the IS and IC cohort densities of tumoral $\mathrm{CD}^{+} \mathrm{LAG}^{+} \mathrm{T}$ cells $\left(31.3 \pm 10.1\right.$ cells $/ \mathrm{mm}^{2}$ and $81.4 \pm 24.9$ cells $/ \mathrm{mm}^{2}$, respectively; $\left.P=0.31\right)$ or stromal CD8 ${ }^{+} \mathrm{LAG}^{+} \mathrm{T}$ cells $\left(104 \pm 22.1\right.$ cells $/ \mathrm{mm}^{2}$ and $162.6 \pm 39.9$ cells $/ \mathrm{mm}^{2}$, respectively; $\left.P=0.82\right)$ (Figure 1C).

\section{Tumor immune microenvironment in immunosuppressed patients is altered in premalignant lesions}

We investigated the immune landscape in samples of normal skin, premalignant and malignant lesions to determine its potential role in immune evasion throughout tumorigenesis. ${ }^{20}$ We sought to characterize the shift in immune cell populations throughout tumor evolution from normal skin, to keratinocytic intraepidermal neoplasia (KIN), to invasive cSCC for both IS and IC patients (Figure 2). We could not assess the immune landscape in the normal skin of IC patients owing to a lack of available normal skin specimens for this patient population. For IS patients, the density of stromal CD $8^{+}$lymphocytes increased during the transition from normal skin $\left(86.4 \pm 40.6\right.$ cells $\left./ \mathrm{mm}^{2}\right)$ to $\mathrm{KIN}\left(297.9 \pm 67.4 \mathrm{cells} / \mathrm{mm}^{2}\right)$ to cSCC $\left(352 \pm 94.9\right.$ cells $\left./ \mathrm{mm}^{2} ; P=0.041\right)$, and the transition from normal skin to KIN was associated with a significant increase in $\mathrm{CD}^{+} \mathrm{LAG}^{+} \mathrm{T}$ cells within the tumor $(P=0.0028)$ and stroma $(P=0.051)$ (Figure 
2A). For IC patients, the density of tumoral and stromal $\mathrm{CD} 4^{+}$or $\mathrm{CD} 8^{+}$lymphocytes did not differ significantly between KIN and cSCC (Figure 2B), suggesting that the shifts in T-cell population occur during the transition from normal skin to KIN.

In IS patients, malignant transformation was accompanied by increasing densities of tumoral $\mathrm{CD}^{+} 8^{+} \mathrm{PDL}^{+}$APCs $\left(2.4 \pm 1.2,1.71 \pm 0.9\right.$, and $186.4 \pm 48.9$ cells $/ \mathrm{mm}^{2}$ for normal skin, KIN, and cSCC, respectively; $P=0.0013)$, stromal $C D 68^{+} \mathrm{PDL}^{+}$APCs $(25.4 \pm 10.5,35.7 \pm 10.3$, and $90.3 \pm 105.2$ cells $/ \mathrm{mm}^{2}$, respectively; $\left.P=0.012\right)$, and stromal CD20 ${ }^{+} \mathrm{B}$ cells $(3.9 \pm 9.9,2.15 \pm 3.67$, and $19.23 \pm 15.0$ cells $/ \mathrm{mm}^{2}$, respectively; $P=0.043$ ). Similarly, in IC patients, malignant transformation was accompanied by increasing densities of tumoral $\mathrm{CD} 68^{+} \mathrm{PDL1}^{+} \mathrm{APCs}\left(0.99 \pm 0.99\right.$ and $32.5 \pm 8.76 \mathrm{cells} / \mathrm{mm}^{2}$ for KIN and SCC, respectively; $P=0.022)$ and stromal CD20 $0^{+}$cells $\left(1.39 \pm 0.95\right.$ and $35.70 \pm 12.1 \mathrm{cells} / \mathrm{mm}^{2}$, respectively; $P=0.030)$ as well as stromal $\mathrm{CD} 68^{+} \mathrm{APCs}\left(85.11 \pm 34.5\right.$ and $306.61 \pm 67.9 \mathrm{cells} / \mathrm{mm}^{2}$, respectively; $P=0.038)$.

One of the major tumor immune evasion pathways is maintained by regulation of the expression of the immunosuppressive checkpoint PDL1 by tumor cells. ${ }^{12,14-16,21,22,22}$ In the IS cohort, the density of $\mathrm{CK}^{+} \mathrm{PDL1}^{+}$cells in $\mathrm{KIN}\left(2917 \pm 468.9\right.$ cells $\left./ \mathrm{mm}^{2}\right)$ and SCC $\left(2659 \pm 314.2\right.$ cells $\left./ \mathrm{mm}^{2}\right)$ were higher than that in normal skin $\left(1613 \pm 523.1\right.$ cells $\left./ \mathrm{mm}^{2}\right)$, but these differences were not statistically significant $(P=$ $0.2303)$. In contrast, in the IC cohort, the density of $\mathrm{CK}^{+} \mathrm{PDL} 1^{+}$cells in $\mathrm{KIN}\left(1406 \pm 480.9 \mathrm{cells} / \mathrm{mm}^{2}\right)$ was lower than that in SCC $\left(2251 \pm 369.4\right.$ cells $\left./ \mathrm{mm}^{2}\right)$, but this difference, was not statistically significant $(P=0.506)$. Taken together, these findings suggest that the shifts in immune cell populations in the TME occurs at different times throughout tumorigenesis.

\section{Etiology of immunosuppression impacts the immune cell deficiencies in cSCC TME}

We hypothesized that the etiology of immunosuppression might affect the composition of the immune infiltration in the TME. To test this hypothesis, we analyzed the immune landscape of cSCC and its precursor lesions in patients with different types of immunosuppression (i.e., hematologic malignancies and organ transplant recipients). In patients with hematological malignancies we found a significant 
decrease in the density of $\mathrm{CD} 68^{+}$APCs compared with IC patients; however, the density of $\mathrm{CD} 4^{+}$or $\mathrm{CD} 8^{+}$ T lymphocytes within the tumor or stromal compartment of invasive SCC did not differ significantly between patients with hematological malignancies and IC patients (Figure 3A). An analysis of precursor lesions revealed that the density of tumoral $\mathrm{CD} 8^{+} \mathrm{LAG}^{+} \mathrm{T}$-cells in lymphoma/leukemia patients $(6.11 \pm$ 2.49 cells $/ \mathrm{mm}^{2}$ ) was significantly lower than that in patients with other types of immunosuppression $\left(52.17 \pm 34.7\right.$ cells $\left./ \mathrm{mm}^{2} ; P=0.016\right)$. Compared with patients with other types of immunosuppression, lymphoma/leukemia patients had a higher density of stromal $\mathrm{CD}^{+} \mathrm{T}$ cells in precursor lesions $(8.8 \pm 7.45$ cells $/ \mathrm{mm}^{2}$ vs. $303 \pm 85.7$ cells $\left./ \mathrm{mm}^{2} ; P=0.0107\right)$ but a lower density of CD20 ${ }^{+}$B cells $(7.94 \pm 3.71$ cells $/ \mathrm{mm}^{2}$ vs. $1.28 \pm 0.50$ cells $\left./ \mathrm{mm}^{2} ; P=0.031\right)$.

The immunosuppression associated with organ transplantation differs from that associated with hematological malignancies or other etiologies. ${ }^{20,23-28}$ Many immunosuppressive drugs, such as tacrolimus and sirolimus, inhibit the effector T-lymphocyte activation and proliferation that occurs in response to antigens and cytokines. In addition, calcineurin inhibitors such as tacrolimus may affect keratinocyte differentiation directly. ${ }^{29}$ To investigate the tumor immune microenvironment in organ transplant recipients, we included organ transplant patients with cSCC treated at University of Pennsylvania. The characteristics of the patients in this unique cohort are provided in Supplemental Table 1. We found no significant differences in tumor $\left(\mathrm{CK}^{+}\right)$burden $(P=1.00)$ or tumor cells' PDL1 expression $\left(\mathrm{CK}^{+} \mathrm{PDL1}^{+} ; P=0.231\right)$ between the organ transplant population and IC patients. This analysis revealed that organ transplant patients had a higher density of tumoral and stromal CD68 ${ }^{+}$APCs $(118.1 \pm 42.3$ and $520.9 \pm 196.7$ cells $/ \mathrm{mm}^{2}$, respectively) than IC patients $\operatorname{did}\left(4.2 \pm 2.1\right.$ and $22.6 \pm 10.4$ cells $/ \mathrm{mm}^{2}$, $P=0.001, P<0.001$ respectively; Figure 3B). Organ transplant patients also had a higher density of tumoral CD8 ${ }^{+} \mathrm{T}$ lymphocytes $\left(1484 \pm 719.8\right.$ cells $\left./ \mathrm{mm}^{2}\right)$ than IC patients $\operatorname{did}\left(78.2 \pm 217.2 \mathrm{cells} / \mathrm{mm}^{2}\right.$; $P=0.031$ ). Compared with IC patients, organ transplant patients had significantly fewer tumor and stromal $\mathrm{CD} 4^{+}$cells and stromal $\mathrm{CD} 68^{+} \mathrm{APCs}$, and $\mathrm{CD} 8^{+} \mathrm{LAG}^{+}$cells (Figure $3 \mathrm{~B}$ ).

To gain further insight into the potentially dysregulated mechanisms of antitumor immunity in IS patients, we assessed the relationship between immune cell populations in different specimen 
compartments (i.e., tumor and stroma) in IC and IS patients separately. In IC patients we found high positive correlation coefficients ( $>0.4$, Pearson's) between stromal and tumoral $\mathrm{CD} 8^{+}$cells and the $\mathrm{CD}^{+} \mathrm{LAG}^{+}$subset, but not between other components of the adaptive or innate immune system (Figure 4A). However, in IS patients there was an increased number of stromal and tumoral immune cells highly correlated to each other, including $\mathrm{CD}^{+}, \mathrm{CD} 8^{+} \mathrm{T}$-cells and $\mathrm{CD} 20^{+} \mathrm{B}$ cells (Figure 4B). These findings suggest a loss of regulatory mechanisms that orchestrate the transition between the tumor compartments; this, in turn, allows the unmonitored exchange of cells between these compartments. This may also elude to the cancer evasion of the production of a local immunosuppressive mechanisms.

\section{Disease specific survival in IS patients correlates with the abundance of $\mathrm{CDB}^{+} \mathrm{LAG}^{+}$cells}

Overall, IS patients had worse outcomes than IC patients did (Supplementary Figure 1). We sought to assess the prognostic value of immune cell density. Univariate analysis revealed that the density of CD $68^{+}$ cell and $\mathrm{CD}^{+} \mathrm{LAG}^{+}$cells in the TME predicted both disease-specific survival (DSS, Figure 5 A-D) and disease-free survival (DFS, Figure 5 E-H). Using median expression values as cutoffs (CD68 ${ }^{+}$high vs. $\mathrm{CD} 8^{+}{ }_{\text {low }}$ and $\mathrm{CD} 8^{+} \mathrm{LAG}^{+}{ }_{\text {high }}$ vs. $\mathrm{CD} 8^{+} \mathrm{LAG}^{+}{ }_{\text {low }}$ ), we analyzed the extent to which these cell populations in the stromal and tumoral compartment of cSCC affect DFS and DSS. Compared with those with $\mathrm{CD}^{+}{ }^{+} \mathrm{AG}^{+}{ }_{\text {low }}$ cells in the stroma, IS patients with $\mathrm{CD}^{+} \mathrm{LAG}^{+}{ }_{\text {high }}$ cells in the stroma has worse DSS (hazard ratio, 1.24; 95\% confidence interval, 1.02-1.54; $P=0.001$; likelihood ratio 0.035 , Figure 5D), indicating the impact of dysfunctional cytotoxic T cells on these patients' survival. No immune markers were associated with DFS in the IS cohort. In the IC population, no immune markers were associated with DSS; however, better DFS was associated with $\mathrm{CD} 8^{+}{ }_{\text {high }}$ cells (hazard ratio, $0.67 ; 95 \%$ confidence interval, 0.46-0.94; $P=0.011$; likelihood ratio 0.0655, Figure 5E). These finding suggest that the presence of APCs in the TME is associated with better immune response and enhanced tumor eradication. 


\section{Discussion}

In this study we delineated the significant differences in the immune microenvironment throughout cSCC development between IS and IC patients. Our findings suggest that IS patients have distinct immune infiltration patterns with pre-malignant skin lesions and $\mathrm{cSCC}$ that varies with the etiology of immunosuppression. Interestingly, the major difference seen was in the abundance of APC's and in the distribution of other immune cells within the lesion, i.e., migration between the tumor and stromal compartments; and that patients with high abundance of $\mathrm{CD}^{+} 8^{+}$in their tumors have better outcome and significantly less recurrences. Together with the lack of differences in $\mathrm{T}$ cell (either $\mathrm{CD}^{+}$or $\mathrm{CD}^{+}$), these differences suggest a defective priming of the adaptive response by APC's, rather than, inherently nonfunctioning T cells. ${ }^{30,31}$ These results are encouraging as $\mathrm{T}$ cell priming is clinically actionable; furthermore, given the risk associated with immunotherapy in this patient population (e.g., graft rejection), these findings provide a rational for local activation and priming of $\mathrm{T}$ cells using intralesional injection of, for example toll like receptor (TLR) 9 and CD40 agonists or systemic adoptive T-cell immunotherapy. ${ }^{32} \mathrm{We}$ found that $\mathrm{CD} 68^{+} \mathrm{PDL1}^{+}$cells population increase in the TME during the transition to invasive malignancy. In anti-PD-1 axis therapy-treated patients, high levels of PD-L1 expression in macrophages was associated with longer survival; although we did not investigate the response to immunotherapy, this increase in the number of $\mathrm{CD} 8^{+} \mathrm{PDL1}^{+}$cells suggest an additional role for this cell population in priming of the anti-tumor adaptive immune response. These findings, that describe for the first time the tumor-stroma shifts in immune cell population throughout tumor evolution suggest that in IS patients cSCC cells may evade destruction by inhibiting the ability of APCs to process tumor neoantigens and produce a robust downstream adaptive anti-tumor responses. ${ }^{5,33-35}$

The TME is driven by rich intercellular communications via networks of cytokines, chemokines, and matrix remodeling enzymes. Phenotyping of the TME in various cancers and across various immune statuses has provided important insights into immune responses as well as mechanisms of tumor escape. Further immunophenotyping will lead to the identification of additional therapeutic options for vulnerable 
IS patients. Indeed, understanding the specific TME may not only enable the development of targeted therapies but also direct clinicians in modulating immunosuppressive medications and thus reducing oncologic potential. At present, clinical trials of immunotherapy have largely excluded IS patients. The strong correlation between stromal and tumoral immune cells found in the IS cohort that was not seen in the IC cohort suggests fundamental dysregulation of the highly regulated processes that determine the makeup of the TME. For instance, in IC patients the stromal compartments did not mirror the tumoral compartments. These data indicate dysregulated immune crosstalk and provides rationale to target the signaling events that occur between the innate and adaptive immune systems in IS patients.

Our analysis shows no difference in the distribution of cells associated with the adaptive immune response between the IS and IC patients. Others have posited that a larger density of myeloid cells in the TME later in carcinogenesis portends worse outcomes. ${ }^{36}$ We assessed the expression of the LAG3 phenotypic marker in CD8+ T cells because it a clinically actionable target; also, functionally LAG3 reduces T-cell activation by acting as an inhibitory ligand against CD4 contact sites for MHC class II proteins. Like PDL1, LAG3 may be considered a signal of T-cell activation/exhaustion, thereby portending a poorer immunologic outcome. ${ }^{17-19}$ In the present study, we found that in organ transplant recipients stromal LAG3 levels in $\mathrm{CD}^{+} \mathrm{T}$ cells were lower compared with IC populations with cSCC. Together with our findings that APC's abundance is negatively affected by immunosuppression, these findings suggest that although the adaptive immune system in IS patients is intact, its upstream activation might be disrupted and could potentially be therapeutically targeted.

In IS patients we found that increase in T cells within the TME occurs as early as the precursor lesion developed. Garris et al have recently shown that the efficacy of anti-PD-1 immunotherapy requires intratumoral APCs. ${ }^{37}$ One possible explanation is that APCs can express PD-L1 and bind to PD-1 thus resulting in downstream immune inhibition. However, the increase in $\mathrm{CD}^{+} 8^{+} \mathrm{PDL1}^{+}$cells happens after the malignant transformation, similar to the increase we evidenced in IC patients with cSCC. In melanoma the association of PD-L1 expression in macrophages with overall survival confirms mechanistic findings in mouse models in human tissue and gives a new insight in the clinical significance 
of macrophages in anti-tumor effect after PD-1/PD-L1 pathway blockade. ${ }^{38}$ These findings suggest a highly orchestrated sequence of events that occur at different times throughout tumorigenesis.

Furthermore, our findings indicate that local activation of APCs in IS patient population using oncolytic viruses or TLR agonists has the potential to harness the APCs and induce an effective T cell priming and antitumor response. This might be further augmented with the administration of low dose immune checkpoint blockers to avoid potential toxicities unique for IS patients (e.g., graft rejection).

The etiology of immunosuppression plays a major role in TME development. $\mathrm{T}_{\text {regs }}$ are found within the tumor bed of most malignancies, and a higher concentration of $\mathrm{T}_{\text {regs }}$ portends poorer prognosis. ${ }^{18,39-41}$ A previous study revealed that the Treg-to-CD8 ${ }^{+} \mathrm{T}$ cell ratio in IS transplant patients was significantly higher than that in IC patients. ${ }^{42,43}$ In the present study, we found that organ transplant patients had decreased global number of $\mathrm{T}_{\text {regs }}$ compared with IC patients. This aligns with the $\mathrm{T}$ cellsuppressive effects of the calcineurin inhibitors tacrolimus and cyclosporin as well as those of mycophenolic mofetil, the mainstays of immunosuppressive therapy in the organ transplant population. ${ }^{20,23-28}$ It also suggest a dysregulated influx of $\mathrm{CD}^{+} \mathrm{T}$ cells to the tumoral compartment of cSCC. Taken together, the etiology of the defective antitumor immune response, might be related mostly to $\mathrm{T}$ cell activation or exhaustion rather than migration and proliferation in the TME.

The limitations of the present study included its retrospective nature and small cohort, although this was partially augmented through multi-institutional collaboration. As made clear from this study, the etiology of immunosuppression is paramount to the makeup of the TME as it evolves from premalignancy to malignancy. Future study focusing the specifics related to the etiology of immunosuppression will continue to provide valuable information about this at-risk population. Future directions of study should focus on identifying the specific immunosuppressive therapeutic regimens effecting patients and identifying their subsequent ramifications. Understanding the TME, including its varied tumor-to-stroma relationship, as well as tumor evolution in the IS patients will enable to tailor the use of immunotherapy in this population; e.g., using local versus systemic agents that target immune checkpoint or APCs. For 
such an at-risk population — one whose members often have multiple sites of malignancy — having additional options for treatment is essential.

\section{Methods}

This study was approved by the Institutional Review Boards at MD Anderson Cancer Center, University of Pennsylvania, and Moffitt Cancer Center, and a waiver of informed consent was granted owing to its retrospective nature. All collected data were deidentified, and the study followed the Strengthening the Reporting of Observational Studies in Epidemiology reporting guidelines.

\section{Patient selection}

We queried the Research Electronic Data Capture (REDCap) cSCC registry in the Department of Head and Neck Surgery for patients aged 18 years or older who had a histopathological diagnosis of cSCC of the head and neck (cSCCHN) who had undergone primary surgery at MD Anderson Cancer Center from 1998 to 2020. Patients who received any treatment other than biopsy or local excision before presentation at MD Anderson Cancer Center, those with a follow-up duration of less than 1 month, and those for whom tissue specimens were not available were excluded from the study.

We retrieved demographic, clinicopathological, and treatment data from the electronic medical record. We categorized the patients into two cohorts according to their immunological status (IS or IC). As we described previously, the IS cohort included patients who underwent solid organ or stem cell transplantation; patients with hematopoietic malignant disease or other hematoproliferative disorders; patients with autoimmune disease requiring immunosuppressive therapy; patients with type 1 or 2 diabetes treated with insulin; and patients living with HIV/AIDS. ${ }^{7}$ The IC cohort was comprised of a group of cSCC patients whose age and T-stage distributions matched those of the IS cohort. Staging was performed according to the guidelines of the American Joint Committee on Cancer (8th edition). ${ }^{44}$

\section{Pathological analyses}


Hematoxylin and eosin-stained sections were reviewed by two dermatopathologists (PN and KT) to identify representative tissue cores for the tissue microarray (TMA). For each specimen, two 2-mm tissue cores that included both epithelial and stromal components were selected for the construction of the TMA. Areas of normal epithelium, keratinocytic intraepidermal neoplasia (KIN; including carcinoma in situ and actinic keratosis), and invasive $\mathrm{cSCC}$ were selected from the IS and IC patient samples (Figure 7). We also identified additional organ transplant patients treated at University of Pennsylvania between 2015 and 2020 with whole-slide analysis available in order to augment our analysis of this population due to a small population within our primary institution.

All specimens were then analyzed via immunofluorescent staining to profile cutaneous lesions including actinic keratosis, carcinoma in situ, and sSCC.

\section{Immunofluorescence staining}

Immunofluorescence staining to identify immune cell populations in the TME was performed using the Opal 7-Color multiplex staining kit (PerkinElmer, Hopkinton, MA). TMA sections were deparaffinized in xylene and hydrated in ethanol prior to antigen retrieval with EDTA buffer at $98^{\circ} \mathrm{C}$ for $20 \mathrm{~min}$. Each sample was incubated with two panels of primary antibodies (all from Bethyl Laboratories, Montgomery, TX). Panel 1 included primary antibodies against CK (A500-019A), CD68 (A500-018A), CD8 (A700044), CD4 (A700-015), CD20 (A500-017A), and PDL1 (A700-020). Panel 2 included primary antibodies against CK (A500-019A), CD8 (A700-044), LAG3 (A700-027), CD4 (A700-015), and FOXP3 (A700034). After each cycle of antigen retrival, the slides were incubated with peroxidase and protein blocking solutions (Dako North America, Carpinteria, CA). A secondary antibody conjugated with horseradish peroxidase and the EnVision+ System (Dako) were used for signal detection and amplification. The secondary antibody was associated with the tyramide-conjugated fluorescence dyes Opal 480, Opal 520, Opal 570, Opal 620, Opal 690, and Opal 780. After each staining cycle, the sections were heat-treated to disengage the antigen-antibody complex, while the covalently bound fluorescence-labeled tyramide 
remained on the tissue. Counterstaining of the cell nuclei was performed using DAPI (PerkinElmer). Coverslips were placed onto each stained slide using Fluorescence Mounting Medium (Dako).

\section{Imaging and analysis}

The TMA slides were scanned using the Vectra Polaris multispectral scanning system (PerkinElmer) at 4x to 40x magnification (Figure 1). The scanned images were annotated using Phenochart software and analyzed with inForm version 2.4.8 software (Akoya Biosciences, Marlborough, MA). We performed whole-specimen analysis without a priori selection of specific fields. We annotated tumor $\left(\mathrm{CK}^{+}\right)$and stromal $\left(\mathrm{CK}^{-}\right)$areas using the inForm software for tissue segmentation, which was followed by cell segmentation and phenotyping steps. Cartographic coordinates of each cell were obtained to localize cells within tumor or stroma. Images were analyzed in two batches using the inForm software for cell phenotype enumeration and relationship analysis. Cell numbers were normalized to the size of the tissue segment. The cell counts obtained using each primary antibody were normalized to the analyzed tissue area and described in terms of density (no. cells $/ \mathrm{mm}^{2}$ ).

To study the evolution of the TME throughout tumorigenesis, we compared cell densities between normal epithelium to KIN (carcinoma in situ and actinic keratosis) and invasive cSCC. For the IC population, only the KIN and invasive cSCC samples were available (Supplemental Figure 2).

\section{Statistical analysis}

The cell counts obtained for each primary antibody were normalized by the analyzed tissue area and described as cell density per square millimeter $\left(\mathrm{mm}^{2}\right)$. Associations between categorical and continuous variables were assessed using the Kruskal-Wallis test. Relationships between continuous variables were assessed using the Pearson correlation coefficient.

The primary survival outcome measures were DSS, defined as the time from initial presentation to MD Anderson Cancer Center to the time of death due to $\mathrm{CSCC}$, and DFS, defined as the time from 
initial presentation to the time of recurrence. Differences in survival were assessed using the log-rank test and the univariate Cox proportional hazards regression model. All data analyses were performed using JMP version 15 software (SAS Institute, Cary, NC).

\section{Author Contributions}

MG, FN, DS, PN, JC, MA, AA, MM participated in the design, data acquisition, analysis, interpretation, and drafting of the manuscript.

NG, JM, PS, JA, RG, EB participated in finalizing the manuscript.

TX, SA, KT, AA participated in data acquisition.

All authors contributed to the critical revision and had final approval of the version to be published.

\section{Acknowledgments}

Moran Amit's work is supported by the Disruptive Science Grant of the MoonShot Program (MD Anderson Cancer Center) and institutional research grant (MD Anderson Cancer Center). 


\section{References}

1. $\mathrm{Xu}, \mathrm{M}$. J. et al. Major prognostic factors for recurrence and survival independent of the American Joint Committee on Cancer eighth edition staging system in patients with cutaneous squamous cell carcinoma treated with multimodality therapy. Head Neck 40, 1406-1414 (2018).

2. Daniel E Shumer, N. J. N. N. P. S. Incidence and mortality for cutaneous squamous cell carcinoma: comparison across three continents. Physiol. Behav. 176, 139-148 (2017).

3. Ferrarotto, R. et al. Pilot phase II trial of neoadjuvant immunotherapy in locoregionally advanced, resectable cutaneous squamous cell carcinoma of the head and neck. Clin. Cancer Res. 27, 45574565 (2021).

4. Dr Tanguy Y Seiwert, M. et al. Safety and clinical activity of pembrolizumab for treatment of recurrent or metastatic squamous cell carcinoma of the head and neck (KEYNOTE-012): an openlabel, multicentre, phase 1b trial. Lancet Oncol. May, (2016).

5. Migden, M. R. et al. PD-1 Blockade with Cemiplimab in Advanced Cutaneous Squamous-Cell Carcinoma. N. Engl. J. Med. 341-351 (2018).

6. Mandal, R. et al. The head and neck cancer immune landscape and its immunotherapeutic implications. JCI Insight 1, 1-18 (2016).

7. Tam, S. et al. Association of Immunosuppression with Outcomes of Patients with Cutaneous Squamous Cell Carcinoma of the Head and Neck. JAMA Otolaryngol. - Head Neck Surg. 146, $128-135$ (2020).

8. Schvartsman, G., Perez, K., Flynn, J. E., Myers, J. N. \& Tawbi, H. Safe and effective administration of T-VEC in a patient with heart transplantation and recurrent locally advanced melanoma. J. Immunother. Cancer 5, 1-5 (2017).

9. Williams, I. R. \& Kupper, T. S. Immunity at the surface homeostatic mechanisms of the skin immune system. Life Sci. 58, 1485-1507 (1996).

10. Cela, E. M. et al. Time-course study of different innate immune mediators produced by UVirradiated skin: Comparative effects of short and daily versus a single harmful UV exposure. Immunology 145, 82-93 (2015).

11. Kohli, K., Pillarisetty, V. G. \& Kim, T. S. Key chemokines direct migration of immune cells in solid tumors. Cancer Gene Ther. (2021).

12. Seiwert, T. Y. et al. Safety and clinical activity of pembrolizumab for treatment of recurrent or metastatic squamous cell carcinoma of the head and neck (KEYNOTE-012): an open-label, multicentre, phase 1b trial. Lancet Oncol. 17, 956-965 (2016).

13. Haratani, K. et al. Clinical and immune profiling for cancer of unknown primary site. $J$. Immunother. cancer 7, 251 (2019).

14. Lobl, M., Grinnell, M., Phillips, A., Abels, J. \& Wysong, A. The Correlation Between Immunohistochemistry Findings and Metastasis in Squamous Cell Carcinoma: A Review. Dermatol. Surg. 47, 313-318 (2021).

15. Amoils, M. et al. PD-L1 Expression and Tumor-Infiltrating Lymphocytes in High-Risk and Metastatic Cutaneous Squamous Cell Carcinoma. Otolaryngol. - Head Neck Surg. (United States) 160, 93-99 (2019). 
16. Slater, N. \& Googe, P. PD-L1 expression in cutaneous squamous cell carcinoma correlates with risk of metastasis. J. Cutan. Pathol. 663-670 (2016).

17. Graydon, C. G., Mohideen, S. \& Fowke, K. R. LAG3's Enigmatic Mechanism of Action. Front. Immunol. 11, 3444 (2021).

18. Mittal, D., Gubin, M. M., Schreiber, R. D. \& Smyth, M. J. New insights into cancer immunoediting and its three component phases-elimination, equilibrium and escape. Curr. Opin. Immunol. 27, 16-25 (2014).

19. Waldman, A. D., Fritz, J. M. \& Lenardo, M. J. A guide to cancer immunotherapy: from T cell basic science to clinical practice. Nat. Rev. Immunol. 20, 651-668 (2020).

20. Rangwala, S. \& Tsai, K. Roles of the Immune System in Skin Cancer. Br J Dermatol 165, 953965 (2011).

21. García-Díez, I. et al. PD-L1 Expression is Increased in Metastasizing Squamous Cell Carcinomas and Their Metastases. Am. J. Dermatopathol. 40, 647-654 (2018).

22. Kamiya, S. et al. Association between PD-L1 expression and lymph node metastasis in cutaneous squamous cell carcinoma. Asia. Pac. J. Clin. Oncol. 16, e108-e112 (2020).

23. Sawinski, D. et al. Calcineurin Inhibitor Minimization, Conversion, Withdrawal, and Avoidance Strategies in Renal Transplantation: A Systematic Review and Meta-Analysis. Am. J. Transplant. 16, 2117-2138 (2016).

24. Ulrich, C., Kanitakis, J., Stockfleth, E. \& Euvrard, S. Skin cancer in organ transplant recipients Where do we stand today? Am. J. Transplant. 8, 2192-2198 (2008).

25. Prashar, R. \& Venkat, K. K. Immunosuppression Minimization and Avoidance Protocols: When Less Is Not More. Adv. Chronic Kidney Dis. 23, 295-300 (2016).

26. Euvrard, S. et al. Subsequent skin cancers in kidney and heart transplant recipients after the first squamous cell carcinoma. Transplantation 81, 1093-1100 (2006).

27. Choi, K. Y. \& Schmalbach, C. E. Cutaneous Head and Neck Cancers in the High-Risk Immunosuppressed Population. Otolaryngol. Clin. North Am. 54, 397-413 (2021).

28. Abdel-Wahab, N. et al. Checkpoint inhibitor therapy for cancer in solid organ transplantation recipients: An institutional experience and a systematic review of the literature. J. Immunother. Cancer 7, 1-11 (2019).

29. Wu, X. et al. Calcineurin and ATF3: opposite roles in squamous skin cancer. Physiol. Behav. 176, 139-148 (2017).

30. Sharma, P., Hu-Lieskovan, S., Wargo, J. A. \& Ribas, A. Primary, Adaptive, and Acquired Resistance to Cancer Immunotherapy. Cell 168, 707-723 (2017).

31. Redmond, W. L., Gough, M. J., Charbonneau, B., Ratliff, T. L. \& Weinberg, A. D. Defects in the Acquisition of CD8 T Cell Effector Function after Priming with Tumor or Soluble Antigen Can Be Overcome by the Addition of an OX40 Agonist. J. Immunol. 179, 7244-7253 (2007).

32. Goto, T. et al. Programmed death-ligand 1 on antigen-presenting cells facilitates the induction of antigen-specific cytotoxic $\mathrm{t}$ lymphocytes: Application to adoptive T-cell immunotherapy. $J$. Immunother. 39, 306-315 (2016).

33. Sakaguchi, S. Naturally arising CD4+ regulatory T cells for immunologic self-tolerance and 
negative control of immune responses. Annu. Rev. Immunol. 22, 531-562 (2004).

34. DeLong, P. et al. Regulatory T cells and cytokines in malignant pleural effusions secondary to mesothelioma and carcinoma. Cancer Biol. Ther. 4, 342-346 (2005).

35. Willimsky, G. \& Blankenstein, T. Sporadic immunogenic tumours avoid destruction by inducing T-cell tolerance. Nature 437, 141-146 (2005).

36. Gentles, A. J. et al. The prognostic landscape of genes and infiltrating immune cells across human cancers. Nat. Med. 21, 938-945 (2015).

37. Garris, C. S. et al. Successful Anti-PD-1 Cancer Immunotherapy Requires T Cell-Dendritic Cell Crosstalk Involving the Cytokines IFN- $\gamma$ and IL-12. Immunity 49, 1148-1161.e7 (2018).

38. Toki, M. I. et al. High-plex predictive marker discoveryfor melanoma using Digital Spatial Profiling. Clin Cancer Res 25, 5503-5512 (2020).

39. Graydon, C. G., Mohideen, S. \& Fowke, K. R. LAG3's Enigmatic Mechanism of Action. Front. Immunol. 11, 3444 (2021).

40. Matejuk, A. Skin Immunity. Arch. Immunol. Ther. Exp. (Warsz). 66, 45-54 (2018).

41. Madonna, G. et al. PD-L1 expression with immune-infiltrate evaluation and outcome prediction in melanoma patients treated with ipilimumab. Oncoimmunology 7, 1-8 (2018).

42. Feldmeyer, L. et al. Differential T-cell subset representation in cutaneous squamous cell carcinoma arising in immunosuppressed versus immunocompetent individuals. Exp. Dermatol. 25, 245-247 (2016).

43. Zhang, S. et al. Increased Tc22 and Treg/CD8 Ratio Contribute to Aggressive Growth of Transplant Associated Squamous Cell Carcinoma. PLoS One 8, (2013).

44. Amit, M. et al. Elective neck dissection versus observation in patients with head and neck cutaneous squamous cell carcinoma. Cancer 1-8 (2021). 
Table 1. Primary cohort patient demographics, staging, and treatment modalities

\begin{tabular}{|c|c|c|c|}
\hline Characteristic & Immunosuppression $(\mathrm{n}=61)$ & Immunocompetent $(\mathrm{n}=42)$ & P value \\
\hline Age (median, range), years & $69.9 \pm 11.3$ & $68.8 \pm 12.8$ & 0.6845 \\
\hline $\operatorname{Sex}(n, \%)$ & & & 0.0400 \\
\hline$M$ & $60(98 \%)$ & $37(88 \%)$ & \\
\hline$F$ & $1(1 \%)$ & $5(11 \%)$ & \\
\hline Race/ethnicity (n, \%) & & & 0.4612 \\
\hline White & $60(98 \%)$ & $40(95 \%)$ & \\
\hline Black & 0 & $1(2 \%)$ & \\
\hline Hispanic & $1(1 \%)$ & $1(2 \%)$ & \\
\hline \multicolumn{4}{|l|}{ Reason for Immunosuppression (n, \%) } \\
\hline Leukemia/lymphoma & $43(69 \%)$ & & \\
\hline Autoimmune disease requiring intervention & $5(8 \%)$ & & \\
\hline Insulin-dependent diabetes mellitus & $5(8 \%)$ & & \\
\hline HIV/AIDS & $4(6 \%)$ & & \\
\hline Organ/stem cell transplantation & $4(6 \%)$ & & \\
\hline T category $(n, \%)$ & & & 0.5744 \\
\hline$T x$ & 0 & 0 & \\
\hline Tis & $4(6 \%)$ & $4(9 \%)$ & \\
\hline$T 1$ & $25(40 \%)$ & $12(28 \%)$ & \\
\hline$T 2$ & $8(13 \%)$ & $5(11 \%)$ & \\
\hline$T 3$ & $23(37 \%)$ & $18(42 \%)$ & \\
\hline$T 4$ & $1(1 \%)$ & $3(7 \%)$ & \\
\hline N category $(n, \%)$ & & & 0.3374 \\
\hline$N x$ & $2(3 \%)$ & $2(4 \%)$ & \\
\hline NO & $51(83 \%)$ & $37(88 \%)$ & \\
\hline$N 1$ & $2(3 \%)$ & $1(2 \%)$ & \\
\hline$N 2 a$ & 0 & 0 & \\
\hline$N 2 b$ & $1(1 \%)$ & $2(4 \%)$ & \\
\hline$N 3$ & $5(8 \%)$ & 0 & \\
\hline$M$ category $(\mathrm{n}, \%)$ & & & 1 \\
\hline$M x$ & 0 & 0 & \\
\hline MO & $60(98 \%)$ & $42(100 \%)$ & \\
\hline$M 1$ & $1(1 \%)$ & 0 & \\
\hline Stage (n, \%) & & & 0.6540 \\
\hline 0 & $4(6 \%)$ & $4(9 \%)$ & \\
\hline$I$ & $25(40 \%)$ & $11(26 \%)$ & \\
\hline$I I$ & $6(9 \%)$ & $5(11 \%)$ & \\
\hline$I I I$ & $20(32 \%)$ & $17(40 \%)$ & \\
\hline$I V$ & $6(9 \%)$ & $5(11 \%)$ & \\
\hline \multicolumn{4}{|l|}{ Treatment (n, \%) } \\
\hline Surgery & $61(100 \%)$ & $42(100 \%)$ & \\
\hline Radiation & $19(31 \%)$ & $4(9 \%)$ & \\
\hline Chemotherapy & $3(4 \%)$ & $2(4 \%)$ & \\
\hline
\end{tabular}


Supplemental Table 1- Organ transplantation cohort demographics, T stage, and immunosuppressant therapies

\begin{tabular}{|l|l|}
\hline Organ of transplantation & $\begin{array}{l}\text { Kidney }-6(50 \%) \\
\text { Lung }-5(41 \%) \\
\text { Liver }-1(8 \%)\end{array}$ \\
\hline Age & $67 \pm 7$ years \\
\hline Gender & Male $-7(58 \%)$ \\
& Female $-5(41 \%)$ \\
\hline T stage & T1 $-10(83 \%)$ \\
& T3 $-2(16 \%)$ \\
\hline Ethnicity & White $-12(100 \%)$ \\
\hline Immunosuppression medication at the time of diagnosis & Tacrolimus + mycophenolate mofetil + prednisone $-6(50 \%)$ \\
& Tacrolimus $-1(8 \%)$ \\
& Tacrolimus + prednisone $-3(25 \%)$ \\
& Cyclosporine + prednisone $-2(16 \%)$ \\
\hline
\end{tabular}



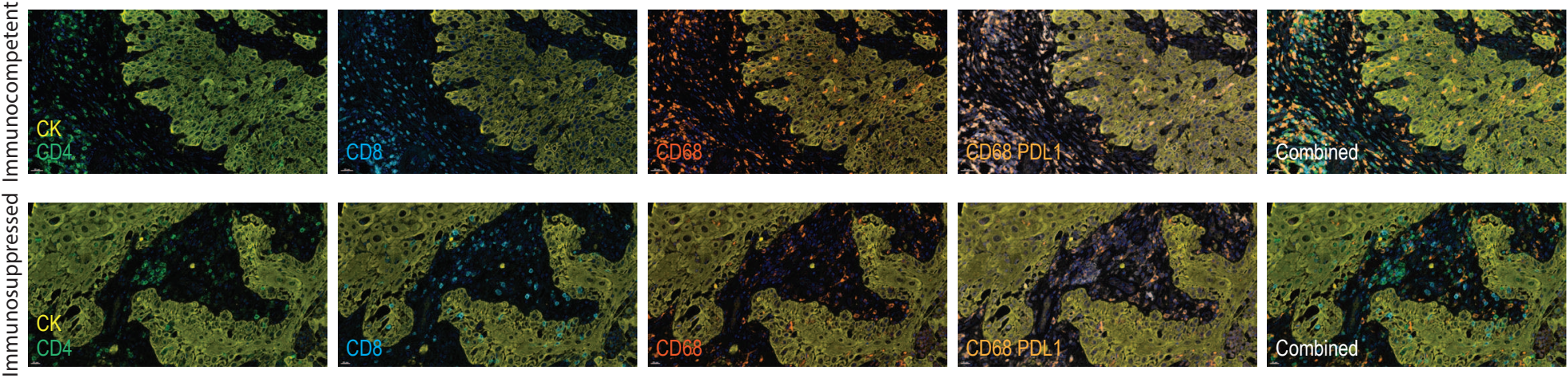

B
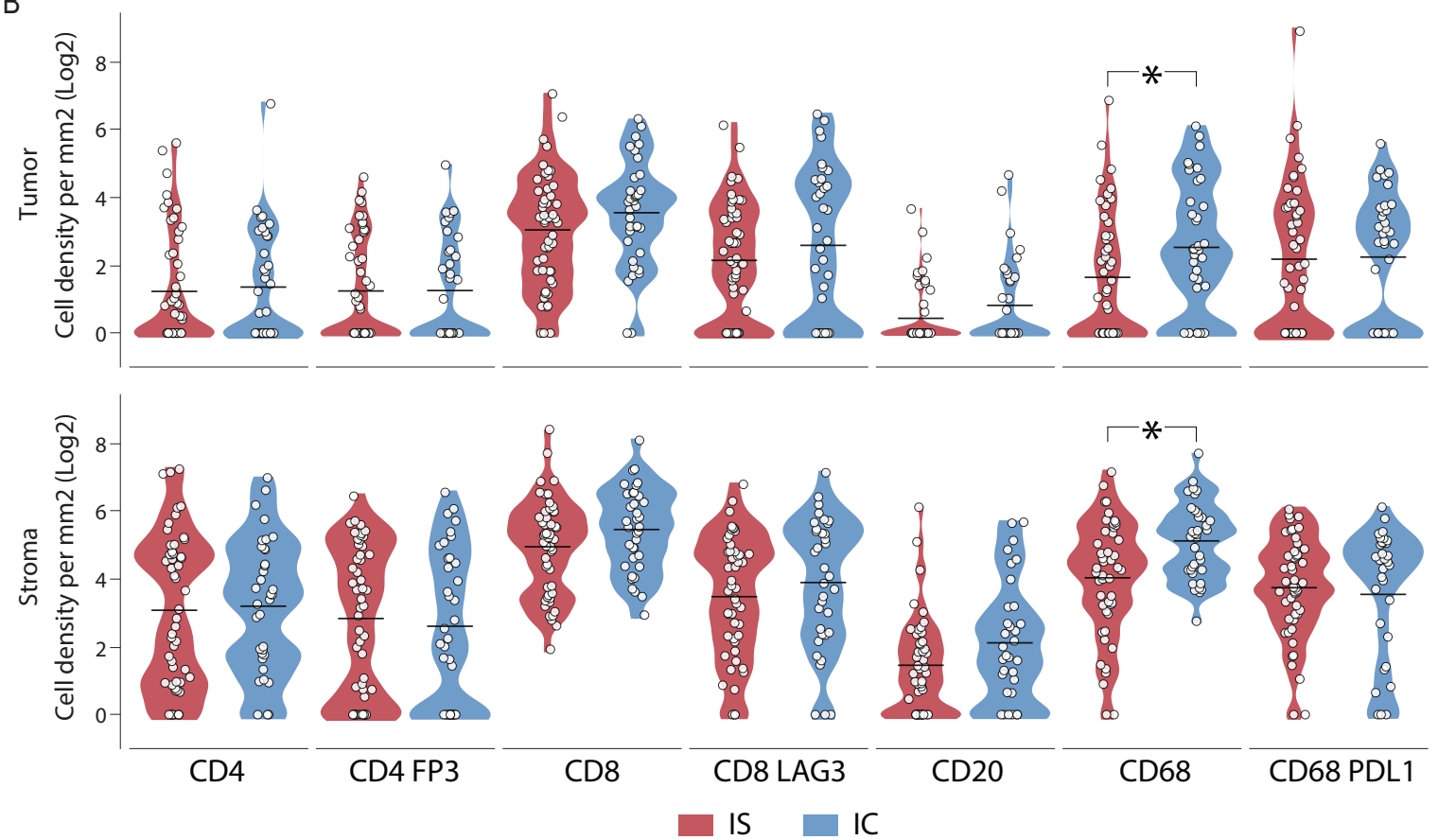

C
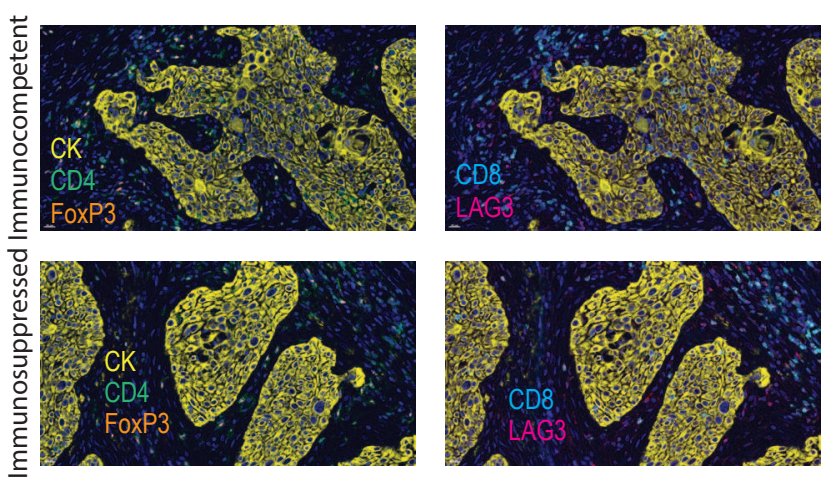

Figure 1: Immune cell infiltration in CSCC of IS and IC patients. A) Representative images of CSCC tissue stained with antibodies against cytokeratin (CK), CD4, CD8, CD68 and PD-L1 counterstained with DAPI. B) The boxplots show the density distribution of immune cell phenotypes (cell per $\mathrm{mm} 2$ ) in the tumor and stromal regions of CSCC samples from immunosuppressed (IS) and immunocompetent (IC) patients. The density of CD68+ cells in the tumor and stromal regions of CSCC from IC patients was significantly higher than in the IS individuals (Wilcoxon test p-value 0.033 and 0.004, respectively). C) Representative images of CSCC tissue stained with antibodies against CD4, CD8, Lag3, FoxP3 and CK counterstained with DAPI. 
A
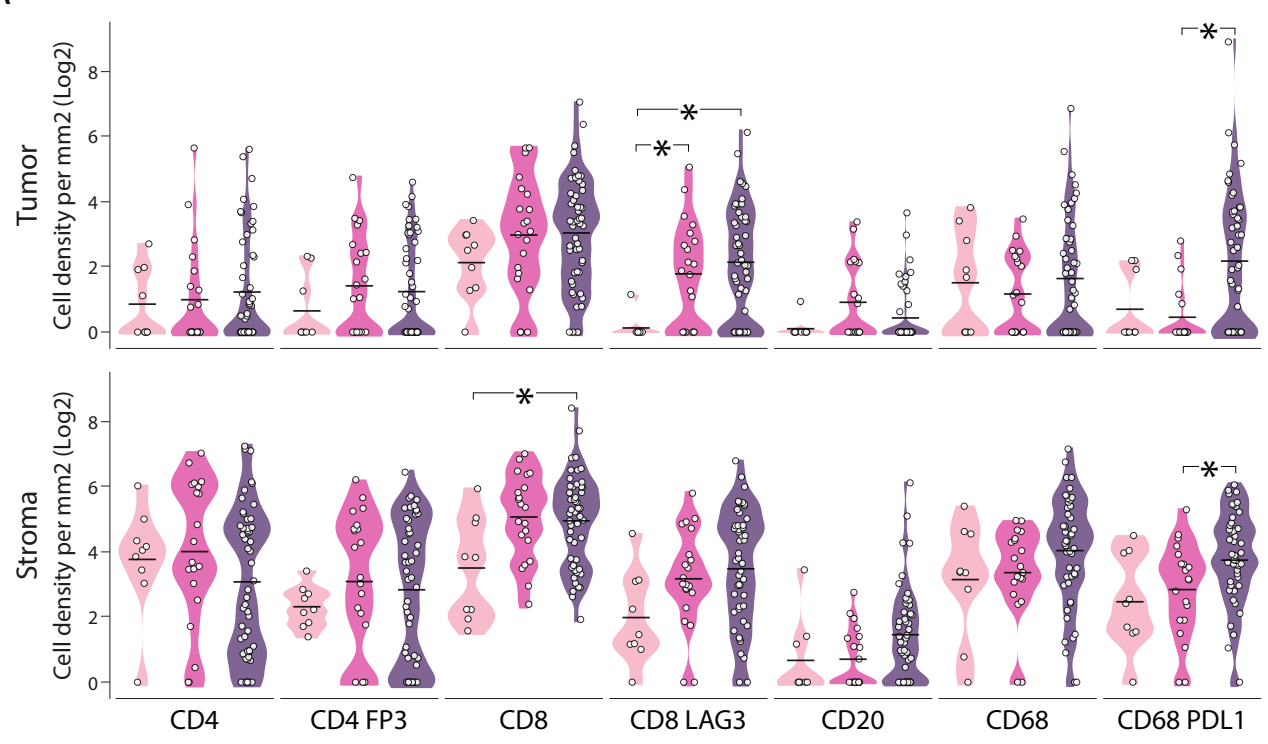

B

Normal Epidermis Keratinocytic Intraepidermal Neoplasia (KIN) Invasive SCC
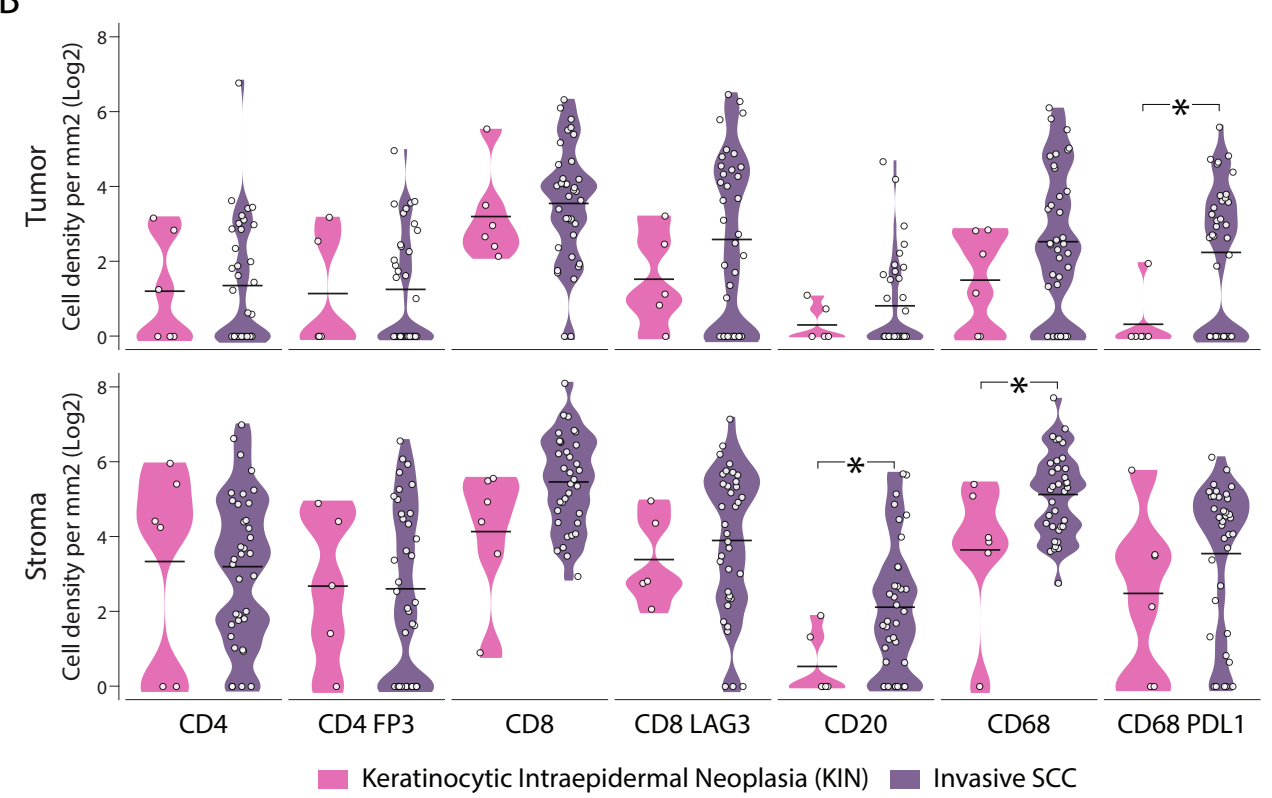

Figure 2: Immune cell infiltration changes throughout the evolution of cSCC. A) The boxplots show the density distribution of immune cell phenotypes (cell per $\mathrm{mm} 2$ ) in tumoral and stromal regions of normal epidermis, keratinocytic intraepidermal neoplasia (KIN), and invasive cSCC samples from immunosuppressed (IS) patients. The density of CD8 LAG3+ and CD68 PDL1+ cells in the tumor region and CD8 and CD68 PDL1+ cells in the stroma, varied significantly among the different normal epidermis, KIN and invasive cSCC (Kruskal-Wallis pvalue $=0.002 ; 0.001 ; 0.042 ;$ and 0.013 , respectively $)$. Significant differences $(p<0.05)$ detected by post-hoc tests are highlighted in the plot (*). B) Boxplots show the immune cell density distribution among KIN and invasive CSCC samples from immunocompetent (IC) patients. The density of tumor CD68 PDL1+ cells was higher among cSCC compared to KIN samples $(p=0.022)$. SCC samples also exhibited higher density of stromal CD8 LAG3+ and CD20+ cells compared to KIN ( $p=0.038$ and 0.030 , respectively). 

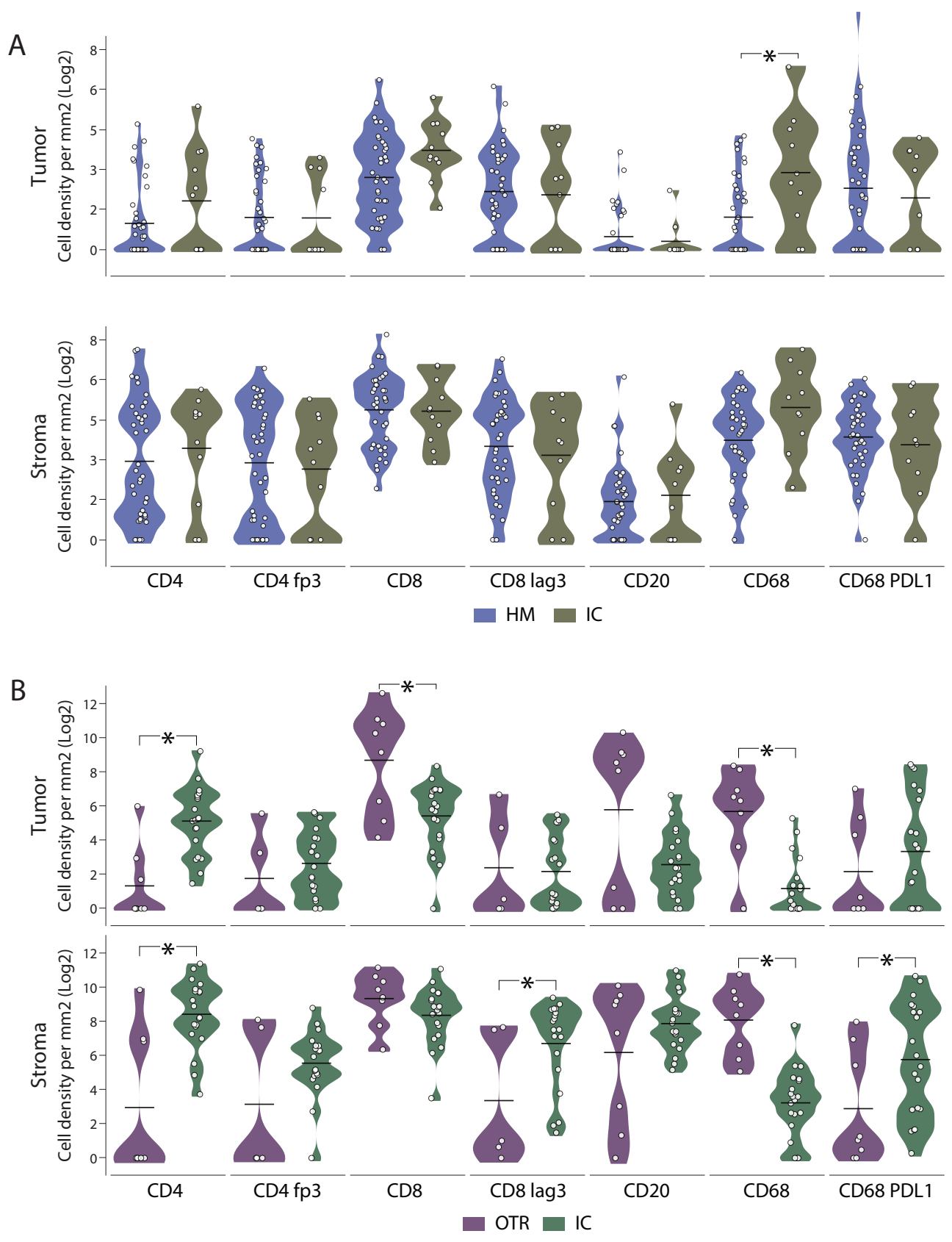

Figure 3: Immune cell infiltration changes according to the cause of immunosuppression. The boxplots show the density distribution of immune cell phenotypes (cell per $\mathrm{mm} 2$ ) in tumoral and stromal regions of cSCC samples from patients with hematological malignancies (HM) (A) and from organ transplant recipients (OTR) (B) in comparison with samples from immunocompetent (IC) patients. Significant differences (Wilcoxon test $p$-value $<0.05$ ) between groups are highlighted in the figure $(*)$. 
A

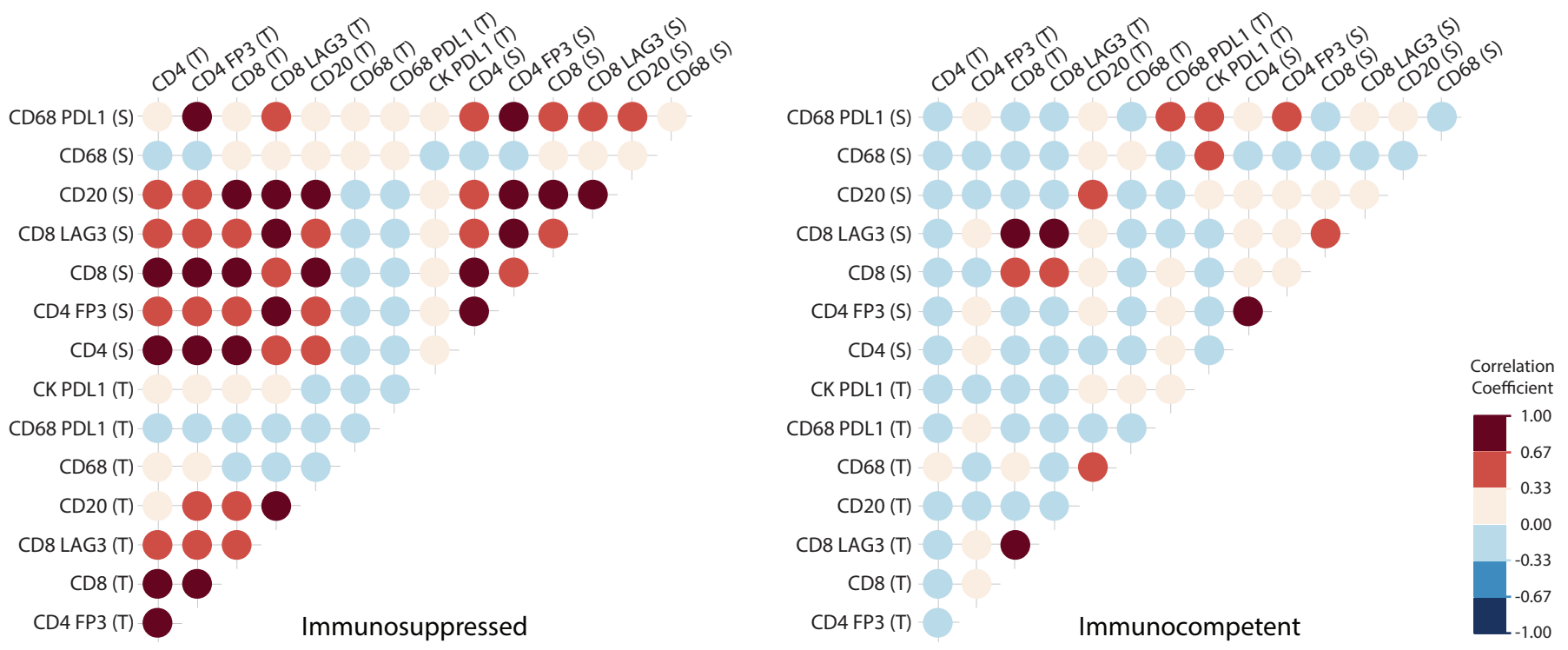

B
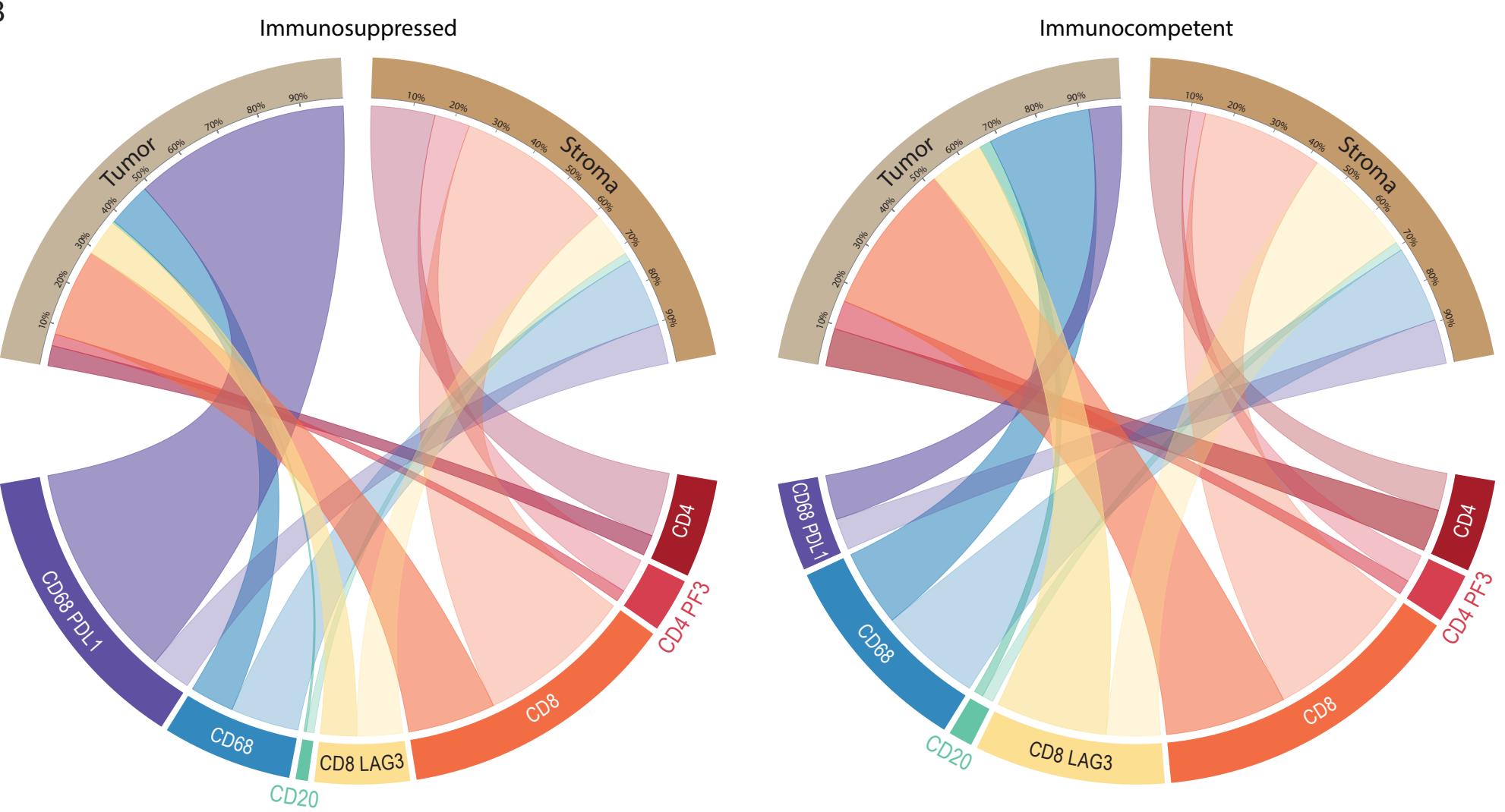

Figure 4: Mapping of immune cell tumor phenotype of CSCC according to the patient immune status. A) The correlogram displays the Pearson's Correlation Coefficient among immune cell phenotypes in the tumor (T) and stromal (S) regions according to each immune group. Darker colors indicate a stronger positive (red) or stronger negative (blue) correlation between cell phenotypes, while brighter colors designate weak correlations. The higher number of darker colors in the immunosuppressed (IS) population suggests loss of tumor derived immune regulation. B) The chord plots depict the abundance of each immune cell phenotype among cSCC samples from immunosuppressed (IS) and immunocompetent (IC) patients and their relative distribution in the tumor and stromal regions. The relative abundance of CD68 PDL1+ cells in IS was higher than in IC patients. These cells comprised more than $50 \%$ of the immune cell population detected in the IS tumor compartment but represented less than $10 \%$ of the cell abundance observed in the tumor region of IC patients. 
A

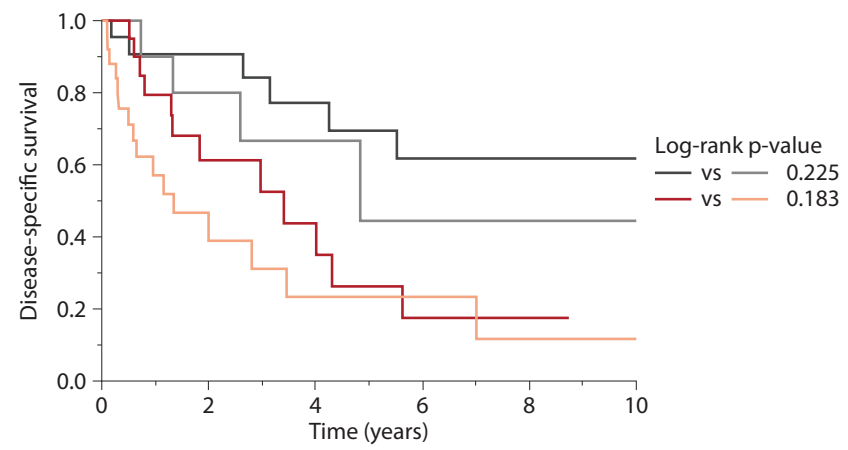

Tumor

—IC CD68 high $\mathrm{n}=23$ (12 events) —IS CD68 high $\mathrm{n}=20$ ( 12 events)

—IC CD68 $8_{\text {low }} n=13$ (5 events) — IS CD68 $8_{\text {low }} n=29$ (16 events)

C

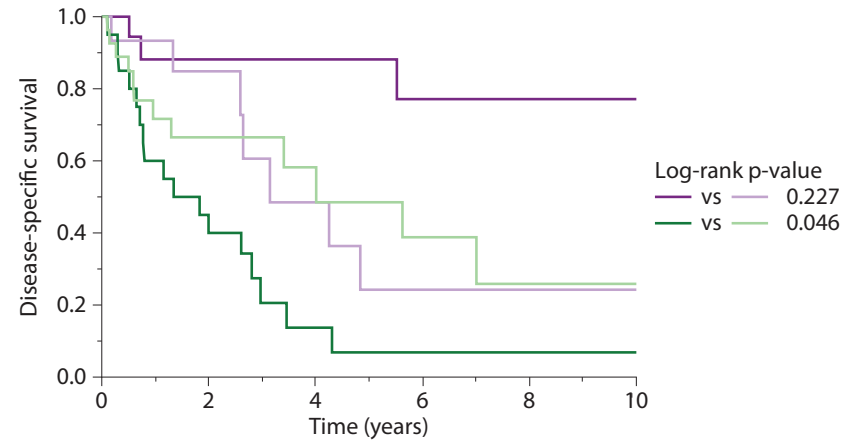

Tumor

—IC CD8 ${ }^{+} \operatorname{lag} 3^{+}{ }_{\text {high }} n=19$ (8 events) —IS CD $8^{+}$lag3 ${ }^{+}{ }_{\text {high }} n=24$ (17 events)

- IC CD8 ${ }^{+}$lag $3^{+}{ }_{\text {low }} n=17$ (9 events) — IS CD8 ${ }^{+}$lag $3^{+}{ }_{\text {low }} n=27$ (12 events)

$E$

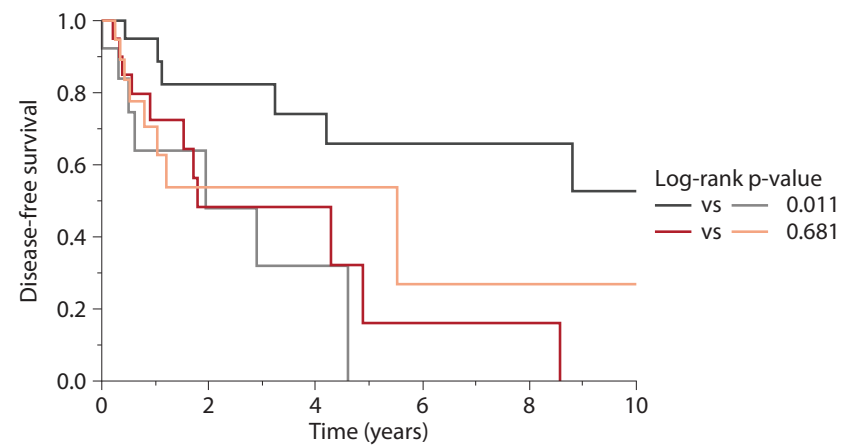

Tumor

—IC CD68 $8_{\text {high }} \mathrm{n}=22$ (6 events) - IS CD68 high $_{\text {nag }} \mathrm{n}=20$ (11 events)

- IC CD68 ${ }_{\text {low }} n=13$ (7 events) - IS CD68 ${ }_{\text {low }} n=28$ (8 events)

G

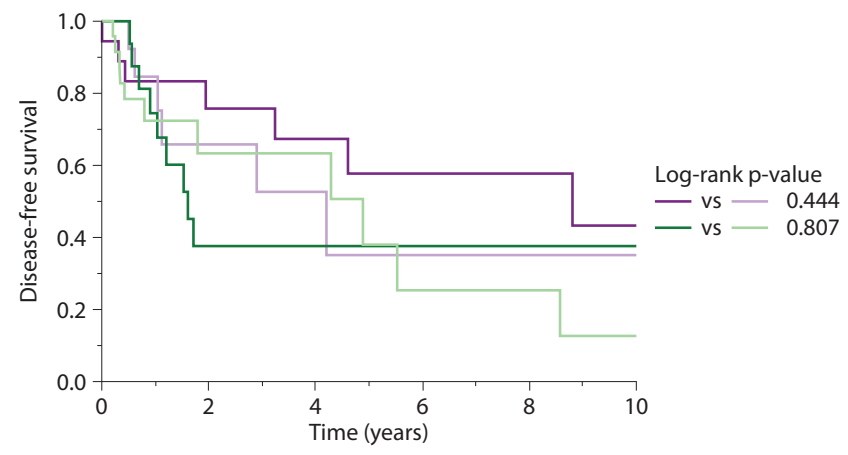

Tumor

- IC CD8 ${ }^{+}$lag3 ${ }_{\text {high }}^{+} \mathrm{n}=18$ (7 events) — IS CD8 ${ }^{+}$lag $3^{+}{ }_{\text {high }} \mathrm{n}=24$ (9 events)

- IC CD $8^{+}$lag $3^{+}{ }_{\text {low }} n=17$ (6 events) —IS CD $8^{+}$lag $3^{+}{ }_{\text {low }} n=26$ (11 events)
B

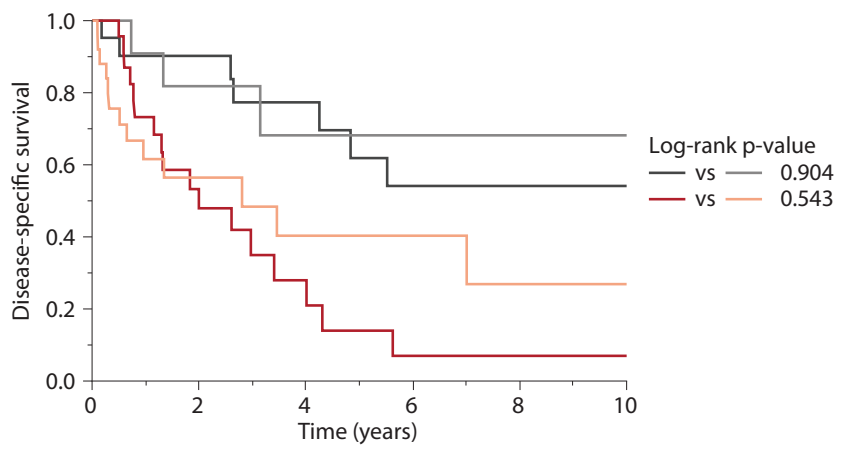

Stroma

- IC CD68 high $_{n} \mathrm{n}=22$ (12 events) —IS CD68 high $\mathrm{n}=24$ (17 events)

-IC CD68 $8_{\text {low }} n=14$ ( 5 events) - IS CD68 ${ }_{\text {low }} n=28$ ( 13 events)

D

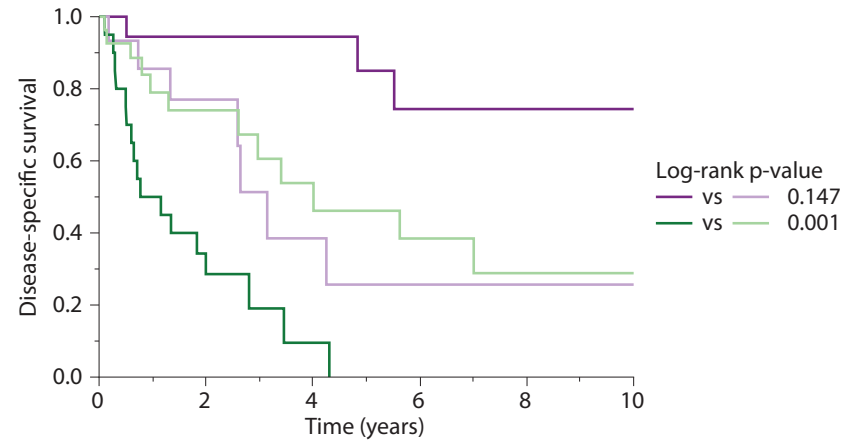

Stroma

— IC CD 8 ${ }^{+}$lag $3^{+}{ }_{\text {high }} \mathrm{n}=19$ (8 events) — IS CD8 ${ }^{+} \operatorname{lag} 3^{+}{ }_{\text {high }} \mathrm{n}=24$ (17 events)

- IC CD8 ${ }^{+}$lag $3^{+}{ }_{\text {low }} n=17$ ( 9 events) - IS CD8 ${ }^{+}$lag $3^{+}{ }_{\text {low }} n=27$ (12 events)

$\mathrm{F}$

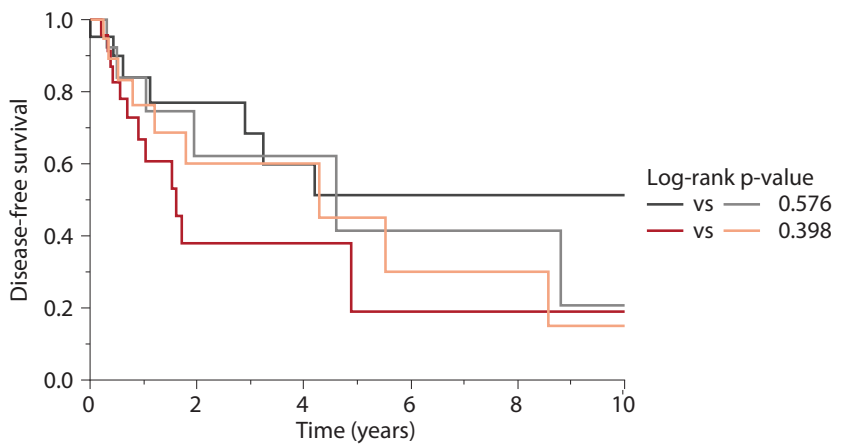

Stroma

- IC CD68 $8_{\text {high }} \mathrm{n}=21$ (7 events) - IS CD68 high $_{n} \mathrm{n}=24$ ( 12 events)

-IC CD68 ${ }_{\text {low }} \mathrm{n}=14$ (6 events) —IS CD68 ${ }_{\text {low }} \mathrm{n}=27$ (9 events)

$\mathrm{H}$

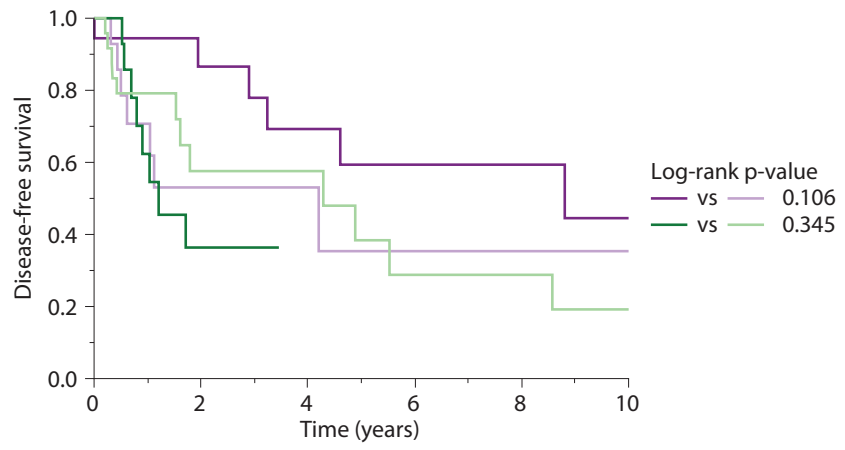

Stroma

- IC CD 8 ${ }^{+}{ }^{\text {lag }} 3^{+}{ }_{\text {high }} \mathrm{n}=18$ (6 events) - IS CD 8 ${ }^{+}$lag $3^{+}{ }_{\text {high }} \mathrm{n}=24$ (8 events)

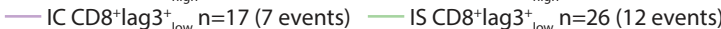

Figure 5: Kaplan Meier curves for disease-specific survival (A-D) and disease-free survival (E-H) for IS vs IC for varied tumor markers up to 10 years 
A

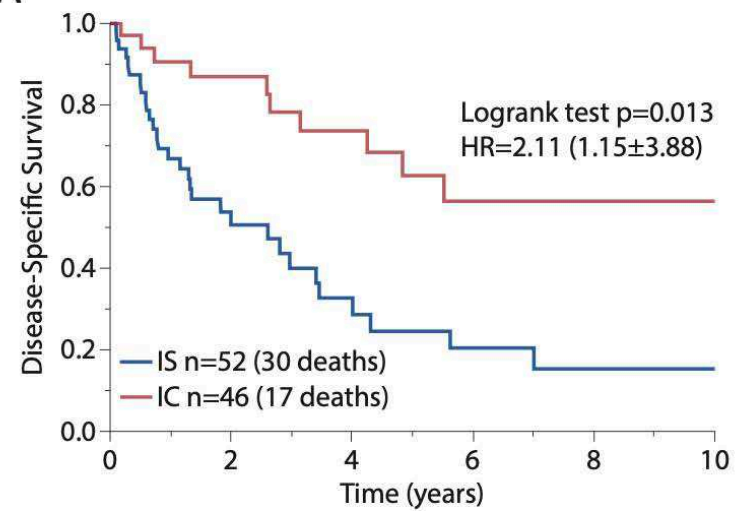

B

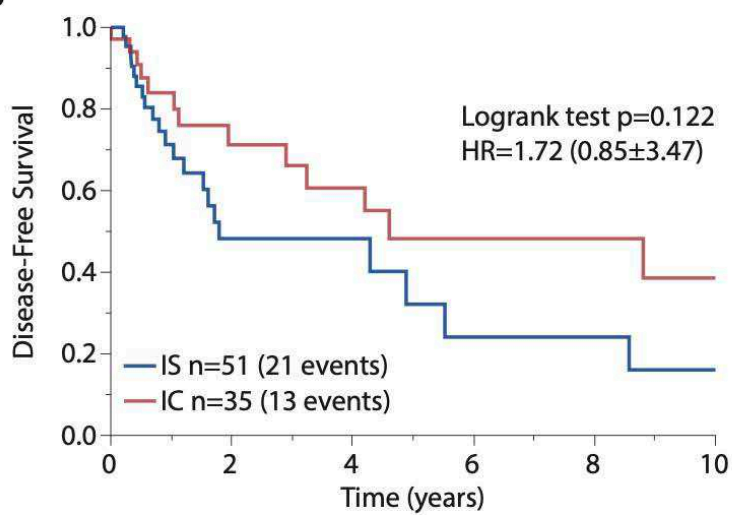

Supplemental Figure 1: Kaplan Meier curves for disease-specific survival and odds-ratio for IS vs IC overall. Blue $=I S$, Red $=I C$

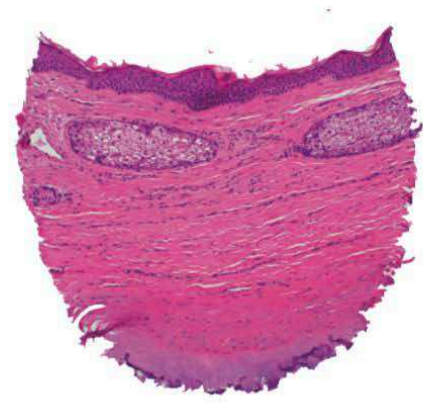

Normal epidermis

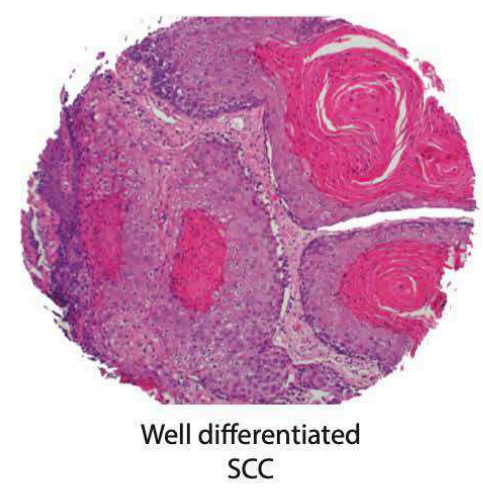

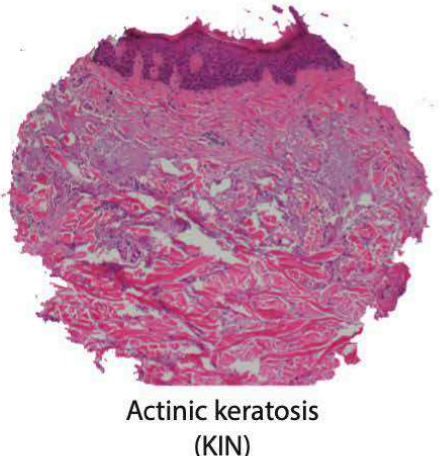

(KIN)

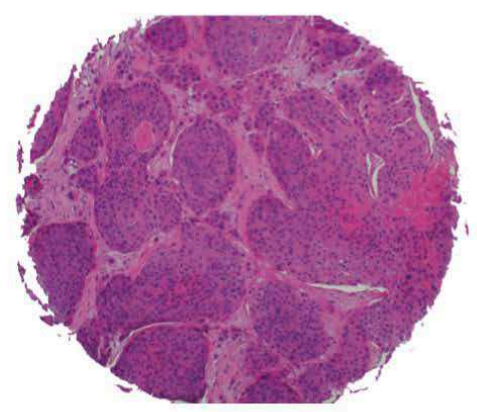

Moderately differentiated SCC

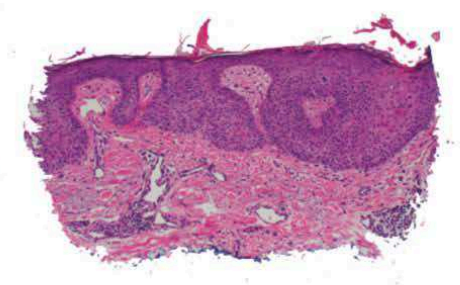

In situ SCC

(KIN)

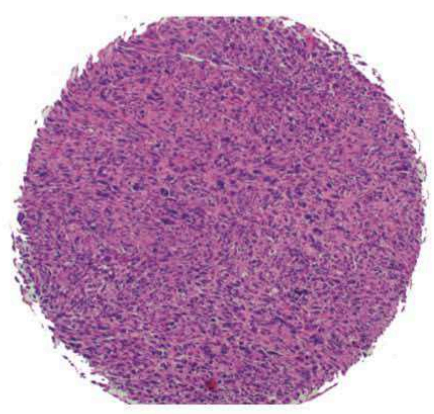

Poorly differentiated SCC

Supplemental Figure 2: Representative H\&E images of the developmental stages of SCC. 